\title{
Ab Initio Study of the Stabilization of Multiply Charged Anions in Water
}

\author{
Eugene V. Stefanovich, Alexander I. Boldyrev, Thanh N. Truong,* and Jack Simons* \\ Henry Eyring Center for Theoretical Chemistry and Department of Chemistry, The University of Utah, \\ Salt Lake City, Utah 84112
}

Received: January 13, 1998; In Final Form: March 13, 1998

\begin{abstract}
Solvation effects on the geometries and electronic and thermodynamic stabilities of a series of small multiply charged polyatomic anions, which are not electronically and thermodynamically stable in the isolated state, have been studied using the generalized conductor-like screening model of solvation. It was found that small doubly charged anions such as $\mathrm{O}^{2-}, \mathrm{CO}_{3}{ }^{2-}$, and $\mathrm{SO}_{4}{ }^{2-}$ are electronically very stable in water with estimated vertical electron detachment energies as high as 6-7 eV. Even the triply charged $\left(\mathrm{BO}_{3}{ }^{3-}, \mathrm{PO}_{4}{ }^{3-}\right.$, and $\left.\mathrm{MgF}_{5}{ }^{3-}\right)$ and quadruply charged $\left(\mathrm{MgF}_{6}{ }^{4-}\right)$ anions are electronically stable in water. In the gas phase $\mathrm{MgF}_{4}{ }^{2-}, \mathrm{MgF}_{5}{ }^{3-}$, and $\mathrm{MgF}_{6}{ }^{4-}$ are not stable toward loss of one $\mathrm{F}^{-}$anion, but the doubly and triply charged anions were found to be thermodynamically stable in water. Surprisingly, the aqueous electron detachment energies are not very strongly dependent on the charge of the anion, and the thermodynamic stabilities of singly, doubly, and triply charged $\mathrm{MgF}_{(2+n)}{ }^{n-}$ anions are very similar (as a result of which one can expect the coexistence of various charged anions in solutions and in melts).
\end{abstract}

\section{Introduction}

When we discuss the stability of multiply charged anions, we must consider various types of stability. The first is an electronic stability. If a multiply charged anion $\mathrm{A}^{n-}$, at its optimal geometry, has a lower electronic energy than the corresponding lower charged anion $\mathrm{A}^{(n-1)-}$ at the same geometry, $\mathrm{A}^{n-}$ is said to be vertically electronically stable. If the electronic energy of $\mathrm{A}^{n-}$ at its optimal geometry is lower than that of $\mathrm{A}^{(n-1)-}$ at its own optimal geometry, $\mathrm{A}^{n-}$ is adiabatically electronically stable. In addition, there is the issue of geometrical stability. If $\mathrm{A}^{n-}$ has all real vibrational frequencies at its optimal geometry, it is locally geometrically stable. This means that this geometry of $\mathrm{A}^{n-}$ corresponds to a local minimum on the potential energy surface. If, in addition to being electronically and geometrically stable, $\mathrm{A}^{n-}$ is more stable than any possible dissociation fragments, it is also thermodynamically stable.

A wide variety of large extended gas-phase molecular systems can attach two or more extra electrons (e.g., $\left.{ }^{-} \mathrm{O}_{2} \mathrm{C}_{(} \mathrm{CH}_{2}\right)_{n} \mathrm{CO}_{2}{ }^{-}$; a wide variety of dianions and higher charged anions have been recently reviewed ${ }^{1-4}$ ). However, for a molecule composed of relatively few atoms, the Coulomb repulsion between the "extra" electrons is more difficult to overcome. During the last 10 years, theoreticians have accumulated a body of data indicating that multiply charged atomic, diatomic, triatomic, and many other multiply charged mononuclear anions (e.g., $\mathrm{CO}_{3}{ }^{2-}, \mathrm{SO}_{4}{ }^{2-}$, $\mathrm{PO}_{4}{ }^{3-}$, etc.), many of which are commonly viewed as building blocks in the condensed phase, are not electronically stable as isolated species. ${ }^{3-9}$

When multiply charged anions are placed into a condensedphase environment, such as in aqueous solution, a substantial enhancement of both the electronic and thermodynamic stabilities can occur due to the solvent polarization field, which lowers the free energy of the charged solutes in a manner approximately proportional to the anion's charge squared. Although the effects of ion stabilization in polar media are qualitatively understood, the magnitudes of these effects are the subject of active investigations. While the stabilizing hydration energy of an anion grows as the ion charge squared, the destabilizing Coulomb repulsion among the "extra" electrons also grows as the charge squared. Thus, it is of interest to determine the maximum negative charge that an anion of a given size can realize and be stable in solution. In the present work, we attempt to address a few such questions concerning the stability of multiply charged anions in water. Specifically, we attempt to ask

1. What is the effect of the water on the geometry of the multiply charged anions?

2. How large is the effect of the water on the electronic stability of the multiply charged anions? In this part of the study, we examined $\mathrm{O}^{2-}, \mathrm{CO}_{3}{ }^{2-}, \mathrm{SO}_{4}{ }^{2-}, \mathrm{PO}_{4}{ }^{3-}, \mathrm{MgF}_{4}{ }^{2-}$, $\mathrm{MgF}_{5}{ }^{3-}$, and $\mathrm{MgF}_{6}{ }^{4-}$. All but $\mathrm{MgF}_{4}{ }^{2-}$ were previously found to be electronically unstable in the isolated state. ${ }^{3-9}$

3. How large is the effect of the water on the thermodynamic stability of multiply charged anions? In this part of the study, we examined $\mathrm{MgF}_{3}{ }^{-}, \mathrm{MgF}_{4}{ }^{2-}, \mathrm{MgF}_{5}{ }^{3-}$, and $\mathrm{MgF}_{6}{ }^{4-}$. All but $\mathrm{MgF}_{3}{ }^{-}$were previously found to be thermodynamically unstable in the isolated state..$^{3-9}$

4. How large a negative ionic charge can be supported in water for anions of the size considered here? We again chose $\mathrm{MgF}_{3}{ }^{-}, \mathrm{MgF}_{4}{ }^{2-}, \mathrm{MgF}_{5}{ }^{3-}$, and $\mathrm{MgF}_{6}{ }^{4-}\left(\mathrm{MgF}_{(2+n)^{n-}}\right)$ to study this problem.

5. How many singly charged ligands can be accommodated around a given central atom in water? We chose $\mathrm{MgF}_{3}{ }^{-}$, $\mathrm{MgF}_{4}{ }^{2-}, \mathrm{MgF}_{5}{ }^{3-}$, and $\mathrm{MgF}_{6}^{4-}\left(\mathrm{MgF}_{(2+n)^{n-}}\right)$ to study this problem.

In this article we present results of quantum chemical studies of the effect of water stabilization on several common multiply charged anions. For these calculations, we used the recently developed generalized conductor-like screening model (GCOSMO $)^{10-16}$ to incorporate the effect of water solvation. This model was earlier successfully applied to many singly charged anions in water ${ }^{12}$ and has shown much promise as a method for obtaining solvation energies for a wide variety of neutral and ionic species. 


\section{Computational Methods}

Some remarks need to be made regarding the definition and physical meanings of various ionization energies that we report. For the isolated species, we present only the vertical ionization energies $\left(\mathrm{IP}_{\mathrm{v}}\right)$ (i.e., total energy differences between $\mathrm{A}^{n-}$ and $\mathrm{A}^{(n-1)-}$ at the optimal geometry of $\mathrm{A}^{n-}$ ), and we denote the isolated species with the label I (e.g. as in $\mathrm{O}^{2-}(\mathrm{I})$ ). The negative electron detachment energies that we report can qualitatively be related to the energy needed to bring "extra" electron to $\mathrm{A}^{(n-1)-}$ to form $\mathrm{A}^{n-}$ with a wave function that is spatially restricted by the $6-31+\mathrm{G}^{*}$ or $6-311+\mathrm{G}^{*}$ basis sets used in our calculations. If one provides more flexibility to the wave function of such electronically unstable anions (e.g., by using a large number of diffuse functions and allowing the wave function to expand in space through mixing with excited configurations), the "extra" electrons will escape. Therefore, the particular values of the negative electron detachment energies are a result of the limited basis set choice. However, because we use the same kind of basis sets for all of the systems considered here, the relative magnitudes of the negative detachment energies offer useful measures of the solvation energies needed to stabilize these species.

We optimized the geometries of the isolated $\mathrm{CO}_{3}{ }^{2-}, \mathrm{SO}_{4}{ }^{2-}$, and $\mathrm{PO}_{4}{ }^{3-}$ species employing analytical gradients with polarized split-valence basis sets $\left(6-311+\mathrm{G}^{*}\right)$ at the MP2(full) level of theory. For calculations on $\mathrm{MgF}_{2}, \mathrm{MgF}_{3}{ }^{-}, \mathrm{MgF}_{4}{ }^{2-}, \mathrm{MgF}_{5}{ }^{3-}$, and $\mathrm{MgF}_{6}{ }^{4-}$ we used $6-31+\mathrm{G}^{*}$ basis sets and nonlocal density functional B3LYP levels of theory. In addition, we checked our DFT results for $\mathrm{MgF}_{(2+n)}{ }^{n-}$ by performing MP2(full) calculations with the larger $6-311+\mathrm{G}^{*}$ basis sets. The fundamental vibrational frequencies, normal coordinates, and zeropoint energies (ZPE) were calculated by standard FG matrix methods. All of these calculations were carried out with the Gaussian 94 program. ${ }^{17}$

For studying the anions in water, which we denote by the label $\mathrm{W}$ (e.g. as in $\mathrm{O}^{2-}(\mathrm{W})$ ), we employed the generalized conductor-like screening model (GCOSMO), ${ }^{10-16}$ which places the solute into a molecular-shaped cavity imbedded in a continuum dielectric medium. The GCOSMO calculations in water were carried out with the same basis sets as for the isolated species. The molecular cavities were defined as molecular surfaces generated by the GEPOL93 algorithm. ${ }^{18}$ The atomic radii (C $1.635 \AA$, O $1.576 \AA$, F $1.28 \AA$, and $\mathrm{S} 2.023 \AA$ ) used in this study were taken from ref 11 , where they have been optimized to reproduce energies of hydration for a representative set of small molecules and singly charged ions. The atomic radius for boron $(1.5 \AA)$ was taken from ref 19 , and the atomic radius of magnesium (1.431 $\AA$ ) was adjusted to fit the experimental hydration energy of the $\mathrm{Mg}^{2+}$ ion. ${ }^{20}$ Our use of atomic radii fitted to hydration energies at $25{ }^{\circ} \mathrm{C}$ and 1 atm guarantees that calculated ground-state energies are actually free energies in solution.

Each cavity surface was divided into 60 surface elements per atomic sphere. The solvent polarization field was represented by point charges located at the centers of each surface element with the magnitude determined self-consistently with the electron density distribution of the solute. The classical dispersion and repulsion contributions to the hydration energy were calculated by using the method of Floris et al. ${ }^{21}$ The pairpotential parameters were taken from the OPLS force field ${ }^{22}$ for all species except $\mathrm{BO}_{3}{ }^{n-}$, for which the MM3 force field ${ }^{23}$ was used. For the cavitation term, we employed the method suggested by Pierotti. ${ }^{24}$ More details on the calculation of these nonelectrostatic contributions are given in ref 12 . For geometry
TABLE 1: Calculated Bond Lengths and Electron Detachment Energies of Multiply Charged Anions in the Isolated State (I) and in Water (W)

\begin{tabular}{lcrcc}
\hline & $\begin{array}{c}R(\mathrm{M}-\mathrm{O}), \\
\AA\end{array}$ & $\begin{array}{c}\mathrm{IP}_{\mathrm{v}}{ }^{\text {Koopmans }} \\
(\mathrm{eV})\end{array}$ & $\begin{array}{c}\mathrm{IP}_{\mathrm{v}}(\mathrm{v})^{\Delta \mathrm{PMP} 2} \\
(\mathrm{eV})\end{array}$ & $\begin{array}{c}\mathrm{IP}_{\mathrm{v}}(\mathrm{a})^{\Delta \mathrm{PMP} 2} \\
(\mathrm{eV})\end{array}$ \\
\hline $\mathrm{O}^{2-}(\mathrm{I})$ & & -6.2 & -6.9 & \\
$\mathrm{O}^{2-}(\mathrm{W})$ & & +8.4 & +7.5 & +3.5 \\
$\mathrm{CO}_{3}{ }^{2-}(\mathrm{I})$ & 1.31 & -1.5 & -3.4 & \\
$\mathrm{CO}_{3}{ }^{2-}(\mathrm{W})$ & 1.30 & +10.0 & +9.9 & +5.7 \\
$\mathrm{SO}_{4}{ }^{2-}(\mathrm{I})$ & 1.52 & +0.7 & -1.6 & \\
$\mathrm{SO}_{4}{ }^{2-}(\mathrm{W})$ & 1.51 & +11.3 & +9.6 & +6.7 \\
$\mathrm{BO}_{3}{ }^{3-}(\mathrm{I})$ & 1.43 & -7.5 & -8.2 & \\
$\mathrm{BO}_{3}{ }^{3-}(\mathrm{W})$ & 1.41 & +8.6 & +8.5 & +5.2 \\
$\mathrm{PO}_{4}{ }^{3-}(\mathrm{I})$ & 1.60 & -5.3 & -5.5 & \\
$\mathrm{PO}_{4}{ }^{3-}(\mathrm{W})$ & 1.57 & +9.7 & +8.5 & +5.7
\end{tabular}

optimization in solution, we used the analytical energy gradients available in the GCOSMO method. ${ }^{13,15}$ Finally, it should be noted that the GCOSMO solvation calculations were implemented in our locally modified version of the Gaussian 92/DFT program. $^{25}$

\section{Findings}

A. Effect of Water on the Geometry of Multiply Charged Anions. The internuclear distances of doubly charged $\mathrm{CO}_{3}{ }^{2-}$ and $\mathrm{SO}_{4}{ }^{2-}$ (see Table 1 ) in water are very close to those in the isolated state, although the latter are electronically unstable. Specifically, the $\mathrm{C}-\mathrm{O}$ and $\mathrm{S}-\mathrm{O}$ bonds shrink by about $0.01 \AA$ when solvated. The bond length contraction is somewhat larger $(0.03 \AA)$ for triply charged $\mathrm{BO}_{3}{ }^{3-}$ and $\mathrm{PO}_{4}{ }^{3-}$ and are also observed by Pyykko and co-workers in a series of works on multiply charged anions. ${ }^{26}$ These small bond length changes are not surprising because, for the anions studied here, the extra electrons are located in nonbonding MOs that cannot substantially disturb the rather strong $\mathrm{C}-\mathrm{O}$ and $\mathrm{S}-\mathrm{O}$ bonds.

In contrast, the solvent effect reduces the bond lengths in $\mathrm{MgF}_{4}{ }^{2-}, \mathrm{MgF}_{5}{ }^{3-}$, and $\mathrm{MgF}_{6}{ }^{4-}$ more significantly and is especially pronounced for $\mathrm{MgF}_{5}{ }^{3-}$ and $\mathrm{MgF}_{6}{ }^{4-}$. In $\mathrm{MgF}_{5}{ }^{3-}$, the axial bond lengths are contracted by $0.2 \AA$ in water. The contraction of the $\mathrm{Mg}-\mathrm{F}$ bonds $(0.28 \AA)$ in $\mathrm{MgF}_{6}{ }^{4-}$ is the largest among all of the multiply charged anions examined here, which is presumably a reflection of the large Coulomb repulsion due to the four extra electrons.

B. Effect of Water on the Electronic Stability of Multiply Charged Anions. For electron detachment energies in water, two different detachment energies were calculated and are denoted $\operatorname{IP}_{\mathrm{v}}(\mathrm{v})$ and $\operatorname{IP}_{\mathrm{v}}(\mathrm{a})$. Both values are calculated as total energy differences between $\mathrm{A}^{n-}$ and $\mathrm{A}^{(n-1)-}$ at the geometry optimized in solution for $\mathrm{A}^{n-}$. However, for the ionization energy $\operatorname{IP}_{\mathrm{v}}(\mathrm{v})$, the total energy of $\mathrm{A}^{(n-1)-}$ is calculated with the charge distribution on the GCOSMO cavity consistent with the charge density of the $\mathrm{A}^{n-}$ ion. This corresponds to assuming that the solvent reaction field remains frozen during the ionization process. For the ionization energy $\operatorname{IP}_{\mathrm{v}}(\mathrm{a})$, the total energy of $\mathrm{A}^{(n-1)-}$ is calculated assuming that the solvent reaction field (e.g., charges on the GCOSMO cavity) is in equilibrium with the charge density of $\mathrm{A}^{(n-1)-}$. Since relaxation of the solvent reaction field lowers the total energy of the solvated $\mathrm{A}^{(n-1)-}$ species, the inequality $\operatorname{IP}_{\mathrm{v}}(\mathrm{v})>\operatorname{IP}_{\mathrm{v}}(\mathrm{a})$ is obtained (the difference between $\operatorname{IP}_{\mathrm{v}}(\mathrm{v})$ and $\operatorname{IP}_{\mathrm{v}}(\mathrm{a})$ is on the order 2.5-4.2 eV (see below)).

Under experimental conditions, the solvent molecules' reorientation component can be safely considered as frozen upon photoionization, while the electronic polarization quickly adjusts to the charge redistribution of the solute. Thus, the experimental 
ionization energy should lie between $\operatorname{IP}_{\mathrm{v}}(\mathrm{v})$ (which allows for no solvent adjustment) and $\operatorname{IP}_{\mathrm{v}}(\mathrm{a})$ (which allows for total solvent adjustment).

While it is commonly accepted that multiply charged atomic anions such as $\mathrm{O}^{2-}, \mathrm{S}^{2-}$, and $\mathrm{N}^{3-}$ occur as building blocks of the solid state, melts, and liquids, there now is consensus that such free atomic ions cannot support two (or more) extra electrons because of the enormous Coulomb repulsion. ${ }^{1-4}$ However, as discussed in the Introduction, in the presence of polar solvent molecules, the electron repulsion is partially compensated by solvation energy. For example, doubly charged $\mathrm{O}^{2-}$ becomes very stable to loss of an electron in water $\left(\mathrm{IP}_{\mathrm{v}}(\mathrm{v})\right.$ $=7.5 \mathrm{eV}$ and $\operatorname{IP}_{\mathrm{v}}(\mathrm{a})=3.5 \mathrm{eV}$; see Table 1). Similarly, $\mathrm{CO}_{3}{ }^{2-}$ and $\mathrm{SO}_{4}{ }^{2-}$, which are electronically unstable in the isolated state, become very stable in water: $\left(\operatorname{IP}_{\mathrm{v}}(\mathrm{v})=9.9 \mathrm{eV}\right.$ for $\mathrm{CO}_{3}{ }^{2-}, \mathrm{IP}_{\mathrm{v}}(\mathrm{v})$ $=9.6 \mathrm{eV}$ for $\mathrm{SO}_{4}{ }^{2-}, \mathrm{IP}_{\mathrm{v}}(\mathrm{a})=5.7 \mathrm{eV}$ for $\mathrm{CO}_{3}{ }^{2-}$, and $\mathrm{IP}_{\mathrm{v}}(\mathrm{a})=$ $6.7 \mathrm{eV}$ for $\mathrm{SO}_{4}{ }^{2-}$ are shown in Table 1).

The triply charged anions $\mathrm{BO}_{3}{ }^{3-}$ and $\mathrm{PO}_{4}{ }^{3-}$ are even more unstable toward electron loss in the gas phase. However, again the situation is very different in solution. In water both are very stable $\left(\mathrm{IP}_{\mathrm{v}}(\mathrm{v})=8.6 \mathrm{eV}\right.$ for $\mathrm{BO}_{3}{ }^{3-}, \mathrm{IP}_{\mathrm{v}}(\mathrm{v})=8.5 \mathrm{eV}$ for $\mathrm{PO}_{4}{ }^{3-}, \mathrm{IP}_{\mathrm{v}}(\mathrm{a})=5.2 \mathrm{eV}$ for $\mathrm{BO}_{3}{ }^{2-}$, and $\mathrm{IP}_{\mathrm{v}}(\mathrm{a})=5.7 \mathrm{eV}$ for $\mathrm{PO}_{4}{ }^{3-}$ are in Table 1) and have solution-phase detachment energies not much less than the aqueous detachment energies of doubly charged anions $\left(\mathrm{CO}_{3}{ }^{2-}\right.$ and $\left.\mathrm{SO}_{4}{ }^{2}\right)$.

The $\mathrm{MgF}_{3}{ }^{-}$anion is a member of the so-called superhalogens $^{27}$ (e.g., an anion with electron detachment energy substantially higher than the electron detachment energies of halogen anions). In our calculation (see Table 2), the vertical electron detachment energy for isolated $\mathrm{MgF}_{3}{ }^{-}$is $7.5 \mathrm{eV}$ at the PMP2(full)/6-311+G* level of theory and $6.6 \mathrm{eV}$ at the B3LYP/6$31+\mathrm{G}^{*}$ level. These numbers can be compared with the 8.14 $\mathrm{eV}$ best value in the literature calculated at the ADC(3)/TZVPSP level of theory by Weikert and Cederbaum. ${ }^{28}$ The isolated $\mathrm{MgF}_{4}{ }^{2-}$ dianion is known to be electronically stable, with a vertical electron detachment energy of $2.98 \mathrm{eV}$ at the ADC(3)/ TZVP-SP level of theory. ${ }^{28}$ Our results on $\mathrm{MgF}_{4}{ }^{2-}(2.2 \mathrm{eV}$ at the MP2(full)/6-311+G* and $1.2 \mathrm{eV}$ at the B3LYP/6-31+G*) differ significantly from the results of Weikert and Cederbaum, but not to an extent that our calculations on the solvation effects are not to be trusted. Finally, the isolated $\mathrm{MgF}_{5}{ }^{3-}$ and $\mathrm{MgF}_{6}{ }^{4-}$ are not electronically stable at either the MP2(full)/6-311+ $\mathrm{G}^{*}$ or B3LYP/6-31+G* levels of theory.

The stabilization effect of water on the electron detachment energies varies substantially in the $\mathrm{MgF}_{(2+n)}{ }^{n-}$ series. The smallest difference between detachment electron energies in water and in the isolated $(5.1 \mathrm{eV})$ is found for $\mathrm{MgF}_{3}{ }^{-}$and the largest (17.4 eV) for $\mathrm{MgF}_{6}{ }^{4-}$. Overall, the aqueous $\mathrm{IP}_{\mathrm{v}}(\mathrm{v})$ and $\mathrm{IP}_{\mathrm{v}}$ (a) remain fairly constant in the $\mathrm{MgF}_{3}{ }^{-}-\mathrm{MgF}_{4}{ }^{2-}-\mathrm{MgF}_{5}{ }^{3-}-$ $\mathrm{MgF}_{6}{ }^{4-}$ series, ranging from 10.2 to $11.7 \mathrm{eV}$ and from 7.7 to $8.7 \mathrm{eV}$, respectively.

\section{Effect of Water on the Thermodynamic Stability of Multiply Charged Anions}

Doubly charged anions such as $\mathrm{MgF}_{4}{ }^{2-}$ and $\mathrm{BeF}_{4}{ }^{2-}$ are known to be thermodynamically unstable, in the isolated state, toward dissociation into $\mathrm{MgF}_{3}^{-}+\mathrm{F}^{-}$and $\mathrm{BeF}_{3}^{-}+\mathrm{F}^{-}$, respectively. ${ }^{28-30}$ Even though thermodynamically unstable, $\mathrm{BeF}_{4}{ }^{2-}$ and $\mathrm{MgF}_{4}{ }^{2-}$ were found to be minima on their potential energy surfaces and to have large Coulomb potential barriers along the decomposition path, which suggests finite lifetimes for these species. ${ }^{28,30}$ One would expect that triply and quadruply charged anions such as $\mathrm{MgF}_{5}{ }^{3-}$ and $\mathrm{MgF}_{6}{ }^{4-}$ would be even more unstable toward loss of one $\mathrm{F}^{-}$anion. That is
TABLE 2: Calculated Bond Lengths and Electron Detachment Energies of $\mathrm{MgF}_{(2+n)}{ }^{n-}$ Anions in the Isolated State (I) and in Water $(\mathrm{W})^{a}$

\begin{tabular}{llcc}
\hline & \multicolumn{1}{c}{$R(\mathrm{M}-\mathrm{O}), \AA$} & $\mathrm{IP}_{\mathrm{v}}(\mathrm{v})(\mathrm{eV})$ & $\mathrm{IP}_{\mathrm{v}}(\mathrm{a})(\mathrm{eV})$ \\
\hline $\mathrm{MgF}_{3}{ }^{-}(\mathrm{I})$ & $1.84(1.85)$ & $+6.6(+7.5)$ & \\
$\mathrm{MgF}_{3}{ }^{-}(\mathrm{W})$ & 1.91 & +11.7 & +8.7 \\
$\mathrm{MgF}_{4}{ }^{2-}(\mathrm{I})$ & $1.95(1.95)$ & $+1.2(+2.2)$ & \\
$\mathrm{MgF}_{4}{ }^{2-}(\mathrm{W})$ & 1.92 & +11.3 & +8.6 \\
$\mathrm{MgF}_{5}{ }^{3-}$ (I) & $2.03 / 2.25(2.07 / 2.18)^{b}$ & $-3.5(-2.0)$ & \\
$\mathrm{MgF}_{5}{ }^{3-}$ (W) & $1.98 / 2.02^{b}$ & +10.7 & +8.2 \\
$\mathrm{MgF}_{6}{ }^{--}$(I) & $2.32(2.35)$ & $-7.2(-6.3)$ & \\
$\mathrm{MgF}_{6}{ }^{4-}$ (W) & 2.04 & +10.2 & +7.7
\end{tabular}

${ }^{a}$ Values in parentheses were calculated at the MP2(full)/6-311+ $\mathrm{G}^{*}$ level of theory for validation of B3LYP/6-31+G* results. ${ }^{b}$ Trigonalbipyramidal structure; first number is an equatorial bond length, and the second number is an axial bond length.

TABLE 3: Calculated Dissociation Energies of the $\operatorname{MgF}_{(2+n)^{n-}}$ Multiply Charged Anions in the Isolated State (I) and in Water $(\mathrm{W})$

\begin{tabular}{ccc}
\hline reaction & $\Delta E^{\mathrm{MP} 2}(\mathrm{eV})$ & $\Delta E^{\mathrm{B} 3 \mathrm{LYP}}(\mathrm{eV})$ \\
\hline $\mathrm{MgF}_{3}{ }^{-} \mathrm{MgF}_{2}+\mathrm{F}^{-}(\mathrm{I})$ & +4.0 & +3.9 \\
$\mathrm{MgF}_{3}{ }^{-}-\mathrm{MgF}_{2}+\mathrm{F}^{-}(\mathrm{W})$ & +0.6 & +0.6 \\
$\mathrm{MgF}_{4}{ }^{2-}-\mathrm{MgF}_{3}-+\mathrm{F}^{-}(\mathrm{I})$ & -1.3 & -1.5 \\
$\mathrm{MgF}_{4}^{2-}-\mathrm{MgF}_{3}-+\mathrm{F}^{-}(\mathrm{W})$ & +0.3 & +0.3 \\
$\mathrm{MgF}_{5}{ }^{3-}-\mathrm{MgF}_{4}{ }^{-}+\mathrm{F}^{-}(\mathrm{I})$ & -6.9 & -7.0 \\
$\mathrm{MgF}_{5}{ }^{3-}-\mathrm{MgF}_{4}^{2-}+\mathrm{F}^{-}(\mathrm{W})$ & +0.1 & +0.1 \\
$\mathrm{MgF}_{6}^{4-}-\mathrm{MgF}_{5}^{3-}+\mathrm{F}^{-}(\mathrm{I})$ & -10.2 & -10.3 \\
$\mathrm{MgF}_{6}{ }^{4-}-\mathrm{MgF}_{5}^{3-}+\mathrm{F}^{-}(\mathrm{W})$ & +0.04 & -0.1
\end{tabular}

indeed what we found in our calculations (Table 3). The $\mathrm{MgF}_{5}{ }^{3-}$ and $\mathrm{MgF}_{6}{ }^{4-}$ anions lie above $\mathrm{MgF}_{4}{ }^{2-}+\mathrm{F}^{-}$and $\mathrm{MgF}_{5}{ }^{3-}$ $+\mathrm{F}^{-}$by 7.0 and $10.3 \mathrm{eV}$, respectively.

In water we found that $\mathrm{MgF}_{3}{ }^{-}$is substantially less stable toward the $\mathrm{MgF}_{2}+\mathrm{F}^{-}$dissociation channel (by $+0.6 \mathrm{eV}$ ) than the free state $($ by $+4.0 \mathrm{eV})$. This is a result of the relatively high solvation energy of $\mathrm{F}^{-}$. The thermodynamic stability toward $\mathrm{F}^{-}$loss is found to decrease with increasing charge of the anion (see Table 3); however $\mathrm{MgF}_{4}{ }^{2-}$ and $\mathrm{MgF}_{5}{ }^{3-}$ are still stable toward loss of $\mathrm{F}^{-}$in water (by 0.3 and $0.1 \mathrm{eV}$, respectively). Our results for the aqueous $\mathrm{MgF}_{6}{ }^{4-}$ are not conclusive. It is clear that dissociation energies of all the $\mathrm{MgF}_{(2+n)}{ }^{n-}$ anions lie in a narrow interval, thus making possible the coexistence of these multiply charged anions in solutions and melts (which was observed experimentally). ${ }^{31}$

\section{Overview}

While multiply charged atomic anions are not stable as free species, they are very electronically stable in water. Many small doubly charged polyatomic anions such as $\mathrm{CO}_{3}{ }^{2-}$ and $\mathrm{SO}_{4}{ }^{2-}$ also are unstable in the isolated state, but in water their vertical detachment energies can be high $(\approx 6-7 \mathrm{eV})$. Even the highly electronically unstable triply charged $\left(\mathrm{BO}_{3}{ }^{3-}, \mathrm{PO}_{4}{ }^{3-}\right.$, and $\left.\mathrm{MgF}_{5}{ }^{3-}\right)$ and quadruply charged $\left(\mathrm{MgF}_{6}{ }^{4-}\right)$ anions are very electronically stable in water. Surprisingly, the $\operatorname{IP}_{\mathrm{v}}(\mathrm{a})$ electron detachment energies are not very strongly dependent on the charge of the anion. For example, the calculated $\operatorname{IP}_{\mathrm{v}}(\mathrm{a})$ values slowly decrease from $+8.7 \mathrm{eV}$ for $\mathrm{MgF}_{3}{ }^{-}$to $+7.7 \mathrm{eV}$ for $\mathrm{MgF}_{6}{ }^{4-}$ in water, while their vertical IPs in the isolated state change from $+6.6 \mathrm{eV}\left(\mathrm{MgF}_{3}{ }^{-}\right)$to $-7.2 \mathrm{eV}\left(\mathrm{MgF}_{6}{ }^{4-}\right)$.

The influence of water on geometries of multiply charged anions depends on the charge of the anion. The effect is rather small for singly and doubly charged anions, but is larger for triply and quadruply charged anions.

Solvation also affects the thermodynamic stability. All of the multiply charged anions examined here are not thermody- 
namically stable toward loss of one electronegative anion ligand in the isolated state, but the doubly and triply charged anions were found to be stable in water to such anion loss. The thermodynamic stabilities of singly, doubly, and triply charged $\mathrm{MgF}_{(2+n)}{ }^{n-}$ anions are very similar, as a result of which one can expect the coexistence of various charged anions in solutions and in melts.

Finally, we remind the reader that our emphasis in this work has been on the effects of solvation on the electronic stability and thermodynamic stability with respect to fragmentation of singly and multiply charged anions. We have not undertaken a study of the overall solvation energy (i.e., the energy required to move the ion from the gas phase into the aqueous phase) of such anions in the present study, because all but $\mathrm{MgF}_{4}{ }^{2-}$ are not electronically stable.

Acknowledgment. This work was supported by NSF Grant CHE9618904 to J.S. and NSF Young Investigator Award to T.N.T.

\section{References and Notes}

(1) Compton, R. N. In Negative Ions, (Multiply Charged Negative Ions); Esaulov, V. A., Ed.; Cambridge University Press: London, 1995.

(2) Kalcher, J.; Sax, A. F. Chem. Rev. 1994, 94, 2291.

(3) Scheller, M. K.; Compton, R. N.; Cederbaum, L. S. Science 1995, 270,1160 .

(4) Boldyrev, A. I.; Gutowski, M.; Simons, J. Acc. Chem. Res. 1996, $29,497$.

(5) Janoschek, R. Z. Anorg. Allg. Chem. 1992, 616, 101. (b) Boldyrev,

A. I.; Simons, J. J. Phys. Chem. 1994, 98, 2298.

(6) Gutowski, M.; Boldyrev, A. I.; Ortiz, J. V.; Simons, J. J. Am. Chem. Soc. 1994, 116, 9262.

(7) Sommerfeld, T.; Scheller, M. K.; Cederbaum, L. S. J. Chem. Phys. 1995, 103, 1057.

(8) Sommerfeld, T.; Scheller, M. K.; Cederbaum, L. S. J. Chem. Phys. 1996, 104, 1464.

(9) Gutowski, M.; Boldyrev, A. I.; Simons, J.; Rak, J.; Blazejowski, J. J. Am. Chem. Soc. 1996, 118, 1173. 253.

(10) Truong, T. N.; Stefanovich, E. V. Chem. Phys. Lett. 1995, 240, (11) 65

(12) Truong, T. N.; Stefanovich, E. V. J. Phys. Chem. 1995, 99, 14700.

(13) Truong, T. N.; Stefanovich, E. V. J. Chem. Phys. 1995, 103, 3709.

(14) Truong, T. N.; Nguyen, U. N.; Stefanovich, E. V. Int. J. Quantum Chem. Quantum Chem. Symp. 1996, 30, 403.
(15) Stefanovich, E. V.; Truong, T. N. J. Chem. Phys. 1996, 105, 2961.

(16) Truong, T. N.; Truong, T.-T., T.; Stefanovich, E. V. J. Chem. Phys. 1995, 107,1881 .

(17) Frisch, M. J.; Trucks, G. W.; Schlegel, H. B.; Gill, P. M. W.; Johnson, B. G.; Robb, M. A.; Cheeseman, J. R.; Keith, T. A.; Peterson, G. A.; Montgomery, J. A.; Raghavachari, K.; Al-Laham, M. A.; Zakrzewski, V. G.; Ortiz, J. V.; Foresman, J. B.; Cioslowski, J.; Stefanov, B. B.; Nanayakkara, A.; Challacombe, M.; Peng, C. Y.; Ayala, P. Y.; Chem, W.; Wong, M. W.; Anders, J. L.; Replogle, E. S.; Gomperts, R.; Martin, R. L.; Fox, D. J.; Binkley, J. S.; DeFrees, D. J.; Baker, J.; Stewart, J. J. P.; HeadGordon, M.; Gonzalez, C.; Pople J. A. GAUSSIAN 94, Revision A.1; Gaussian Inc.: Pittsburgh, PA, 1995.

(18) Pascual-Ahuir, J. L.; Silla, E.; Tunon, I. J. Comput. Chem. 1994, 15,1127 .

(19) Breneman, C. M.; Wiberg, K. B. J. Comput. Chem. 1990, 11, 361.

(20) Friedman, H. L.; Krishnan, C. V. In Water, a Comprehensive Treatise; Franks, F., Ed.; Plenum Press: London and New York, 1973; Vol. 3.

(21) Floris, F. M.; Tomasi, J.; Pascual-Ahuir, J. L. J. Comput. Chem. 1991, $12,784$. 1657 .

(22) Jorgensen, W. L.; Tirado-Rives, J. J. Am. Chem. Soc. 1988, 110,

(23) Allinger, N. L.; Zhou, X.; Bergsma, J. J. Mol. Struct. (THEOCHEM) 1994, $312,69$.

(24) Pierotti, R. A. J. Phys. Chem. 1963, 67, 1840.

(25) Frisch, M. J.; Trucks, G. W.; Schlegel, H. B.; Gill, P. M. W.; Johnson, B. G.; Robb, M. A.; Cheeseman, J. R.; Keith, T. A.; Peterson, G. A.; Montgomery, J. A.; Raghavachari, K.; Al-Laham, M. A.; Zakrzewski, V. G.; Ortiz, J. V.; Foresman, J. B.; Cioslowski, J.; Stefanov, B. B.; Nanayakkara, A.; Challacombe, M.; Peng, C. Y.; Ayala, P. Y.; Chem, W.; Wong, M. W.; Anders, J. L.; Replogle, E. S.; Gomperts, R.; Martin, R. L; Fox, D. J.; Binkley, J. S.; DeFrees, D. J.; Baker, J.; Stewart, J. J. P.; HeadGordon, M.; Gonzalez, C.; Pople J. A. GAUSSIAN 92/DFT, Revision A.1; Gaussian Inc.: Pittsburgh, PA, 1995.

(26) (a) Hotokka, M.; Pyykko, P. Chem. Phys. Lett. 1989, 157, 415. (b) Pyykko, P. Mol. Phys. 1989, 67, 871. (c) Pyykko, P. Chem. Phys. Lett. 1989, 156, 337. (d) Pyykko, P.; Zhao, Y. Mol. Phys. 1990, 70, 701.

(27) (a) Gutsev, G. L.; Boldyrev, A. I. Chem. Phys. 1981, 56, 277. (b) Gutsev, G. L.; Boldyrev, A. I. Adv. Chem. Phys. 1985, 61, 169. (c) Gutsev, G. L.; Boldyrev, A. I. Usp. Khim. 1987, 51, 889.

(28) Weikert, H.-G.; Cederbaum, L. S. J. Chem. Phys. 1993, 99, 8877.

(29) (a) Wurthwein, E.-U.; Krogh-Jespersen, M.-B.; Schleyer, P. v. R. Inorg. Chem. 1981, 20, 3663. (b) Boldyrev, A. I.; Charkin, O. P. Koord. Khim. 1982, 8, 618 .

(30) Weikert, H.-G.; Cederbaum, L. S.; Tarantelli, F.; Boldyrev, A. I. Z. Phys. D 1991, 18, 299.

(31) Robert, E.; Olsen, J. E.; Gilbert, B.; Ostvold, T. Acta Chem. Scand. 1997, 51,379 . 